\title{
Introduction to the Special Section on Sexual Health in Gay and Bisexual Men
}

\author{
Brian Mustanski ${ }^{1} \cdot$ Jeffrey T. Parsons $^{2,3}$
}

Published online: 28 July 2015

(c) Springer Science+Business Media New York 2015

In 2014, we organized an invited meeting of some of the leading scholars studying various aspects of sexual health in gay and bisexual men. Building on an earlier meeting we hosted in 2012 on gay and bisexual male couples and sexual health that resulted in a special section of Archives of Sexual Behavior (Mustanski \& Parsons, 2014), this second meeting expanded the focus on romantic relationships to other interpersonal influences on sexual health such as social/sexual networks. Talks with this focus illustrated the pitfalls and potential of research on gay male couples, and the role that network science can play in understanding sexual health, HIV transmission risk behaviors, and health disparities among gay and bisexual men.

A second theme of this meeting was how researchers can create interventions that are responsive to the multiple and often co-occurring psychosocial health inequities experienced by gay and bisexual men. The term "syndemic" (Singer, 1994) has been used to describe these co-occurring epidemics, and substantial research has documented their existence and relevance to HIV/AIDS among gay and bisexual adult (e.g., Mimiaga et al., 2015b; Parsons, Grov, \& Golub, 2012; Stall et al., 2003) and young men (e.g., Herrick, Stall, Egan, Schrager, \& Kipke, 2014; Mustanski, Garofalo, Herrick, \& Donenberg, 2007) as well as

Brian Mustanski

brian@northwestern.edu

1 Department of Medical Social Sciences, Northwestern University Feinberg School of Medince, 625 N. Michigan Ave., Suite 2700, Chicago, IL 60611, USA

2 Department of Psychology, Hunter College and the Graduate Center of the City University of New York, New York, NY, USA

3 Center for HIV/AIDS Educational Studies and Training (CHEST), New York, NY, USA relevance to other outcomes like suicidality (Mustanski, Andrews, Herrick, Stall, \& Schnarrs, 2014). While the relevance of these psychosocial health issues has become clear, what has been less clear is how interventions can be responsive to multiple health issues simultaneously. In this regard, talks examined a broad range of formative and intervention-based research on what are considered the major syndemic conditions that drive sexual risk behaviors among gay and bisexual men (substance use, depression and mental health, trauma related to childhood sexual abuse and intimate partner violence, and sexual compulsivity).

Finally, crossing both areas of focus, the role of methodological considerations, measurement, and decision making, as well as the unique health disparities faced by ethnic and racial minority gay and bisexual men was examined. Papers presented at this conference were invited for submission and to undergo peer review for consideration for publication in this special section of Archives of Sexual Behavior.

The first set of articles addresses network science, couplesbased approaches, and other interpersonal influences on the sexual health of gay and bisexual men. Neighborhood-level influences on HIV status were examined by analyzing neighborhood-level data from the US Census and other public sources and individual-level data from a longitudinal study of young men who have sex with men (YMSM) living in Chicago (Phillips et al., 2015). Using data from an intensive sub-sample of participants from the same longitudinal study, Birkett, Kuhns, Latkin, Muth, and Mustanski (2015) look specifically at the sexual networks of these Chicago-based YMSM and how individual, partner, and network characteristics are related to sexual health. Moving to Los Angeles, the next article takes advantage of the emergence of geosocial networking applications to identify how social network composition is related to substance use among gay and bisexual men (Holloway, 2015). Stephenson, White, and Mitchell (2015) present results from a sample 
of partnered gay and bisexual men recruited via Facebook to better understand the associations between sexual agreements and perceptions of the HIV prevalence among sex partners and broader populations. Finally, the role of early adolescent attachment to parents and peers and how this is associated with relationship milestones in later adolescence, mental health, and main partner relationship quality among gay, bisexual, and lesbian youth is examined (Starks, Newcomb, \& Mustanski, 2015).

The second set of articles emphasizes the role of syndemics in the sexual health, particularly HIV transmission risk behaviors, of gay and bisexual men. Safren, Perry, Blashill, O'Cleirigh, and Mayer (2015) address concerns that have been expressed regarding the costs associated with intensive (i.e., more than a few individual sessions) HIV-related behavioral interventions and show clearly that the costs associated with the clinical treatment for someone who becomes HIV-positive outweigh the costs of delivering interventions which focus on multiple syndemic conditions. The next two articles highlight the mechanisms that might link minority stress to psychosocial syndemics (Pachankis, 2015) and the feasibility and acceptability of a pilot intervention targeting methamphetamineusing gay and bisexual men (Carrico et al., 2015). Next, syndemic conditions and their association with sexual risk behavior among gay and bisexual men in Latin America (Mimiaga et al., 2015a) and Canada (Tulloch et al., 2015) are examined. This section concludes with two articles which focus in depth on the complex issues surrounding two individual syndemic conditions: childhood sexual abuse (Boroughs et al., 2015) and sexual compulsivity (Parsons, Rendina, Moody, Ventuneac, \& Grov, 2015).

The final set of articles begins with a systematic review of longitudinal studies predicting sexual risk behaviors over time among gay and bisexual men (Huebner \& Perry, 2015). The conclusion is that current theoretical models of sexual risk in this population may be inadequate and require adaption or expansion. Following this is an article that proposes a framework for understanding sexual decision making among gay and bisexual men that tries to go beyond consideration of individual-level traits and factor in situational and event-level processes (Rendina, 2015). The section concludes with three articles highlighting the unique needs relevant to the sexual health of gay and bisexual men of color, including an examination of the economic factors that are related to the sexual health of HIV-positive men in Puerto Rico (Rodriguez-Diaz, Jovet-Toledo, Ortiz-Sanchez, Rodriguez-Santiago, \& VargasMolina, 2015), a study to better understand race-based sexual preferences and stereotypes in a racially diverse sample of YMSM (Newcomb, Ryan, Garofalo, \& Mustanski, 2015), and an online study designed to better understand racial and ethnic differences in access to technology, social media use, and sexual risk among HIV-positive gay and bisexual men (Hirshfield, Grov, Parsons, Anderson, \& Chiasson, 2015).
The articles in this special section illustrate the advances that have been made in considering the impact of interpersonal factors and co-occurring health issues on the sexual health of gay and bisexual men. Many of these articles call for translational research that will apply the findings from these studies to the creation of prevention and clinical interventions to improve the health of gay and bisexual men. Such interventions should leverage the increase in understanding of structural, network, social, and interpersonal influences rather than privileging the characteristics of the individual.

Society is rapidly changing in its social acceptance and policies toward the LGBT community. As we write this commentary, the Supreme Court of the United States has just issued a ruling that same-sex couples have a constitutional right to legally be married (Supreme Court of the United States, 2015) thereby making same-sex marriage legal throughout the United States. Such policy changes have documented impacts on the health of LGBT individuals (Hatzenbuehler, 2014), and we look forward to future research that will characterize the effects of these changing social policies on the community.

\section{References}

Birkett, M., Kuhns, L., Latkin, C., Muth, S., \& Mustanski, B. (2015). The sexual networks of racially diverse young men who have sex with men. Archives of Sexual Behavior. doi:10.1007/s10508-015-0485-5.

Boroughs, M. S., Valentine, S. E., Ironson, G., Shipherd, J. C., Safren, S., Taylor, S. Wade, ... O'Cleirigh, C. (2015). Complexity of childhood sexual abuse: Predictors of current post-traumatic stress disorder, mood disorders, substance use, and sexual risk behavior among adult men who have sex with men. Archives of Sexual Behavior. doi:10.1007/s10508-015-0546-9.

Carrico, A. W., Gomez, W., Siever, M. D., Discepola, M. V., Dilworth, S. E., \& Moskowitz, J. T. (2015). Pilot randomized controlled trial of an integrative intervention with methamphetamine-using men who have sex with men. Archives of Sexual Behavior. doi:10.1007/ s10508-015-0505-5.

Hatzenbuehler, M. L. (2014). Structural stigma and the health of lesbian, gay, and bisexual populations. Current Directions in Psychological Science, 23, 127-132. doi:10.1177/0963721414523775.

Herrick, A., Stall, R., Egan, J., Schrager, S., \& Kipke, M. (2014). Pathways towards risk: Syndemic conditions mediate the effect of adversity on HIV risk behaviors among young men who have sex with men (YMSM). Journal of Urban Health, 91, 969-982. doi:10. 1007/s11524-014-9896-1.

Hirshfield, S., Grov, C., Parsons, J. T., Anderson, I., \& Chiasson, M. A. (2015). Social media use and HIV transmission risk behavior among ethnically diverse HIV-positive gay men: Results of an online study in three U.S. states. Archives of Sexual Behavior. doi:10.1007/s105 08-015-05135-5.

Holloway, I. W. (2015). Substance use homophily among geosocial networking application using gay, bisexual and other men who have sex with men. Archives of Sexual Behavior. doi:10.1007/ s10508-015-0581-6.

Huebner, D. M., \& Perry, N. S. (2015). Do behavioral scientists really understand HIV-related sexual risk behavior? A systematic review of longitudinal and experimental studies predicting sexual behavior.Archives of Sexual Behavior. doi:10.1007/s10508-015-0482-8. 
Mimiaga, M., Biello, K. B., Robertson, A. M., Oldenburg, C. E., Rosenberger, J. G., O'Cleirigh, C., ... Safren, S. (2015a). High prevalence of multiple syndemic conditions associated with sexual risk behavior and HIV infection among a large sample of Spanish and Portuguese speaking men who have sex with men in Latin America. Archives of Sexual Behavior. doi:10.1007/s10508-015-0488-2.

Mimiaga, M., O’Cleirigh, C., Biello, K. B., Robertson, A. M., Safren, S. A., Coates, T. J., ... Mayer, K. H. (2015b). The effect of psychosocial syndemic production on 4-year HIV incidence and risk behavior in a large cohort of sexually active men who have sex with men. Journal of Acquired Immune Deficiency Syndromes, 68, 329336. doi:10.1097/QAI.0000000000000475.

Mustanski, B., Andrews, R., Herrick, A., Stall, R., \& Schnarrs, P. W. (2014). A syndemic of psychosocial health disparities and associations with risk for attempting suicide among young sexual minority men. American Journal of Public Health, 104, 287-294. doi:10.2105/AJPH.2013.301744.

Mustanski, B., Garofalo, R., Herrick, A., \& Donenberg, G. (2007). Psychosocial health problems increase risk for HIV among urban young men who have sex with men: Preliminary evidence of a syndemic in need of attention. Annals of Behavioral Medicine, 34, 37-45. doi:10.1080/08836610701495268.

Mustanski, B., \& Parsons, J. T. (2014). Introduction to the special section on sexual health in gay and bisexual male couples. Archives of Sexual Behavior, 43, 17-19. doi:10.1007/s10508-013-0228-4.

Newcomb, M., Ryan, D., Garofalo, R., \& Mustanski, B. (2015). Racebased sexual stereotypes and their effects on sexual risk behavior in racially diverse young men who have sex with men. Archives of Sexual Behavior. doi:10.1007/s10508-015-0495-3.

Pachankis, J. E. (2015). A unified minority stress pathways approach for treating psychosocial syndemic conditions among gay and bisexual men. Archives of Sexual Behavior. doi:10.1007/s10508-015-0480-х.

Parsons, J. T., Grov, C., \& Golub, S. A. (2012). Sexual compulsivity, cooccurring psychosocial health problems, and HIV risk among gay and bisexual men: Further evidence of a syndemic. American Journal of Public Health, 102, 156-162. doi:10.2105/AJPH.2011.300284.

Parsons, J. T., Rendina, H. Jonathon, Moody, R., Ventuneac, A., \& Grov, C. (2015). Syndemic production and sexual compulsivity/hypersexuality in highly sexually active gay and bisexual men: Further evidence for a three group conceptualization. Archives of Sexual Behavior. doi:10.1007/s10508-015-0574-5.
Phillips, G., II, Birkett, M., Kuhns, L., Hatchel, T., Garofalo, R., \& Mustanski, B. (2015). Neighborhood-level associations with HIV infection among young men who have sex with men in Chicago. Archives of Sexual Behavior. doi:10.1007/s10508-014-0459-z.

Rendina, H. J. (2015). When parsimony is not enough: Considering dual processes and dual levels of influence in sexual decision making. Archives of Sexual Behavior. doi:10.1007/s10508-015-0569-2.

Rodriguez-Diaz, C. E., Jovet-Toledo, G. G., Ortiz-Sanchez, E. J., Rodriguez-Santiago, E. I., \& Vargas-Molina, R. L. (2015). Sexual health and socioeconomic-related factors among HIV-positive men who have sex with men in Puerto Rico. Archives of Sexual Behavior. doi:10.1007/s10508-015-0481-9.

Safren, S. A., Perry, N. S., Blashill, A. J., O'Cleirigh, C., \& Mayer, K. H. (2015). The cost and intensity of behavioral interventions to promote HIV treatment for prevention among HIV-positive men who have sex with men. Archives of Sexual Behavior. doi:10.1007/ s10508-015-0455-3.

Singer, M. (1994). AIDS and the health crisis of the U.S. urban poor: The perspective of critical medical anthropology. Social Science and Medicine, 39, 931-948.

Stall, R., Mills, T. C., Williamson, J., Hart, T., Greenwood, G., Paul, J., ... Catania, J. A. (2003). Association of co-occurring psychosocial health problems and increased vulnerability to HIV/AIDS among urban men who have sex with men. American Journal of Public Health, 93, 939-942. doi:10.2105/Ajph.93.6.939.

Starks, T., Newcomb, M.E., \& Mustanski, B. (2015). A longitudinal study of interpersonal relationships among lesbian, gay, and bisexual adolescents and young adults: Mediational pathways from attachment to romantic relationship quality. Archives of Sexual Behavior. doi:10.1007/s10508-015-0492-6.

Stephenson, R. B., White, D., \& Mitchell, J. W. (2015). Sexual agreements and perception of HIV prevalence among an online sample of partnered men who have sex with men. Archives of Sexual Behavior. doi:10.1007/s10508-015-0532-2.

Supreme Court of the United States. (2015). Obergefell et al v. Hodges. Retrieved 27 June 2015, from http://www.supremecourt.gov/opinions/ 14pdf/14-556_3204.pdf.

Tulloch, T., Rotondi, N. K., Ing, S., Myers, Ted, Calzavara, L., Loutfy, M., $\&$ Hart, T. (2015). Retrospective reports of developmental stressors, syndemics, and their association with sexual risk outcomes among gay men. Archives of Sexual Behavior. doi:10.1007/s10508-015-0479-3. 